\title{
THE EFFECTS OF FREE ROTATE GESTURES IN MULTI-TOUCH SCREEN DESIGN ON CHILDRENS' ACHIEVEMENT IN LEARNING SHAPE FOR PRE- SCHOOL CHILDREN
}

\author{
Fadhlina Mohd Razali ${ }^{1}$, Nor Azah Abdul Aziz ${ }^{2}$, Siti Aishah Salim ${ }^{3}$, Roznim Mohamad \\ Rasli $^{4}$ \& Nur Farah Zulkefly ${ }^{5}$ \\ fadhlina@fskik.upsi.edu.my ${ }^{1}$, azah@fskik.upsi.edu.my², aisyah@fskik.upsi.edu.my ${ }^{3}$; \\ roznim@fskik.upsi.edu.my ${ }^{4}$,mailto:nurfarahzulkefly@gmail.com ${ }^{5}$ \\ Faculty of Art, Computing and Creative Industry, Sultan Idris Education University, \\ Malaysia
}

\begin{abstract}
The purpose of this study is to investigate the effects of free rotate gesture used in multi-touch screen design on pre-school children's achievement in learning shape. Multi-touch screen design enables users to perform multiple finger gestures such as free rotate, pinch and spread. The gestures are often selected because it is similar to reallife movements. Free rotate gesture enables users to rotate the objects on screen which can enhance the interaction between users and virtual objects. As the actions are natural, spontaneous and easy to learn, it has been widely used in learning purposes. Therefore, it is important to investigate how these free rotate gesture affect children's achievement in learning shape as the children can interact with the virtual shape naturally. The study involves 20 childrens aged 5 to 6 years old from National Children Development Research Centre (NCDRC). The samples had been given a pre-test and post-test about shapes before and after they used the mobile application of Learning Shape which include the free rotate gestures. Then the pre-test dan post-test score had been analyzed by using Paired Samples T-Test in SPSS by comparing its means. The results indicated that the post-test mean is higher than the pre-test mean with significant value is less than .05. It shows that the free rotate gestures can effects children's achievement in learning shape. The study also observes children's interaction while using the mobile application. The results shows that the children are happy and can understand the topic more easily because they can interact with the virtual shape naturally. As for conclusion, the free rotate gestures is an important factor that should be be taken into consideration when designing mobile applications for pre-school children.
\end{abstract}

Keywords: Multi-touch Gestures, Touch Screen, Free Rotate Gestures, Pre-School Children

\section{INTRODUCTION}

iPads, tablets or other mobile devices has become an influential tool in life and acquirements in social, academic, cognitive and language due to maximization of interactive mobile technology nowadays [1]. Interactive mobile technology are becoming more embedded, pervasive and networked by upgrade capabilities for rich social interactions, context awareness and internet connectivity which can have a vast impact on learning [2]. Such technologies add a new dimension to the learning activities because of the multi-touch interactions they can support with other learners and the learning environment. Multi-touch interactions are speeding rapidly, and most people including children have used this kind of interaction when practicing games or other activities on multi touch device. Essentially, multi touch device is a surface where multiple active contact points can be sensed simultaneously, which is able to acquire touch information at reasonable spatial and temporal resolution [3]. 
A diverse technology introduces different particular interaction to perform specific task which are used by children. For instance desktop computer familiarized with point-and-click and drag-and-drop tasks, while touch devices familiarized with multi-touch interaction: zoomin and zoom-out, and rotate [4]. A past study indicates that children can perform normal gestures but there is no experiment was conducted in rotation gesture with a focus on the children's achievement on such gesture [5]. In the context of this study, multi-touch device enables users to perform free rotate gesture which is two fingers are used. The first finger regulates the centre of rotation, while the second regulates the rotation angle [6]. Basically, a touch from second finger onto the touch screen initiates the rotation while the object is selected. The change in rotation depends on how proficient the children to handle the free rotate gesture on multi-touch device. Furthermore, researchers are used the free rotate gesture on tablet application that is designed for this study to explore how this gesture influences children's achievement in learning shape.

\section{LITERATURE REVIEW}

When dealing with technologies such as introducing new child mobile application, school management should first consider school learning preferences and learning outcomes rather than just the technology aspects. Such technologies have the potential to support pre-school children centred, independent, differentiated and personalised learning. The uses of technologies depend on the level of education where research on them ranges from nurseries to universities [7]. Regrettably, related research among pre-schoolers is minimal which reassure the researchers to study about it in-depth.

Despite that, the relation between physical interactions with a touchscreen device and learning environment has been explored previously. Agostinho et al. [8] mentioned that finger tracing on tablet device could enhance learning performance which support mathematical problem solving. Similarly, a study found that participants in the drag condition were more accurate than those in the tap condition which asked participants to complete a number line estimation task by either tapping or dragging on a tablet [9]. A past research [10] evaluating the effect of smartphones and tablets in preschool and primary school as well as focused on teachers' ability to document, analyse and communicate children's learning, rather than the children themselves engage with the technology. According to Omar [11] technology is quite popular trend among children in Malaysia. Children often see grown up groups incessantly with the technology which motivate them to practically use it. They will experience a better learning environment if they handle it in right way. Therefore, researchers intend to look up on preschool children's achievement in learning shape by using multi-touch device or known as tablet. In the context of this study, researchers highlighted on multi-touch screen design embedded with free rotate gesture only as equivalent studies do not focus on this gesture.

Rotation is defined as the radial motion of the thumb and the index finger around a fixed point [12], as shown in Figure 1. Two-finger gestures could develop high levels of muscle activations. Moreover, the researchers strongly suggested that 90-degree rotations were 
preferable to free rotations, but such a preference depended on the specific purposes of applications (based on the guidelines of Windows 8 and Apple iOS). In addition, the slowest rotation is when the finger moves horizontally. In other studies, rotation angle had a positive value for clockwise rotations and a negative value during anticlockwise rotations [13]. However, such a convention was not examined in this study.

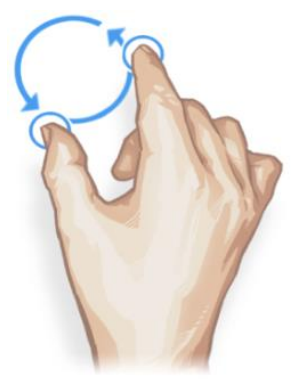

Figure 1. Free Rotate Gesture

According to Bertolo et al. [14], multi-touch interaction technique allows users to control the 3D scene with two fingers. Bertolo et al. presented students' experiment results by comparing three different interaction techniques to rotate 3D scenes based on different metaphorical interactions: multi-touch inputs, movement of tablets captured with gyroscope sensors and head movements captured by face-tracking camera. They found that the mean time to complete the task was 41.2s for multi-touch techniques, 45.8s for gyroscope techniques and 108.6s for face-tracking techniques. Moreover, many students choose multi-touch techniques based on user preferences. They found that multi-touch technique was very easy while gyroscope techniques were just easy and face-tracking techniques were difficult. They also reported that the use of different techniques were fun and intuitive for multi-touch and fun techniques for gyroscope techniques and face-tracking techniques.

In this study, the topic of shape was selected because it is conversant with the preschool children. Shapes are one of the topics of early childhood education that preschool children must learn to identify the names of common two-dimensional shapes, such as circles, squares, triangles, ovals, and rectangles. The strategies and activities that have been listed in this study [15] can help them to recognize and compare shapes. For instance, one of the strategies used entails introducing the children the various kinds of triangles, such as equilateral, isosceles, and scalene triangles. Then, students need to compare such shapes by examining the different sizes of the shapes. Students have to explain the differences between two-dimensional shapes (flat) and three-dimensional shapes (solid) afterwards. For example by asking them the right questions, such as "How a book and a piece of paper are similar?" and "How do they differ from one another?". In this respect, preschool children can improved their understanding about geometry by classify the shape from different angles and three-dimensional objects [16]. 


\section{RESEARCH METHOD}

\section{A. Subjects}

Twenty preschool children participated in this study. Participants were from years 5 and 6 in a preschool from National Children Development Research Centre (NCDRC), UPSI. Parent/carer consent to participate was obtained.

\section{B. Task and Procedures}

The study consisted of three consecutive phases: pre-test, learning and post-test. The participants were divided into two groups based on their ages. One group consisted of 5 year olds, and the other comprised 6 year olds.

\section{a. Pre-Test}

Two groups had been given different pre-test questions related to shapes according to their ages. All participants needed to answer all the 10 questions. For children by age 5 , the questions were just about to match and colour of the same shapes (circle, square, triangle, rectangle and crescent). On the other hand, the questions for children by age 6 were same but with other shape (oval, triangle, rectangle, crescent and star). All the answer will be checked and give scored.

\section{b. Learning}

All participants were tested on the mobile application Learning Shape which compromised with three main games for preschool children (see Figure 2). When they were using free rotate gesture to learn about shapes, the participants were observed by their behaviour react to such gesture and simultaneously asking them related to their free rotate gesture experience.

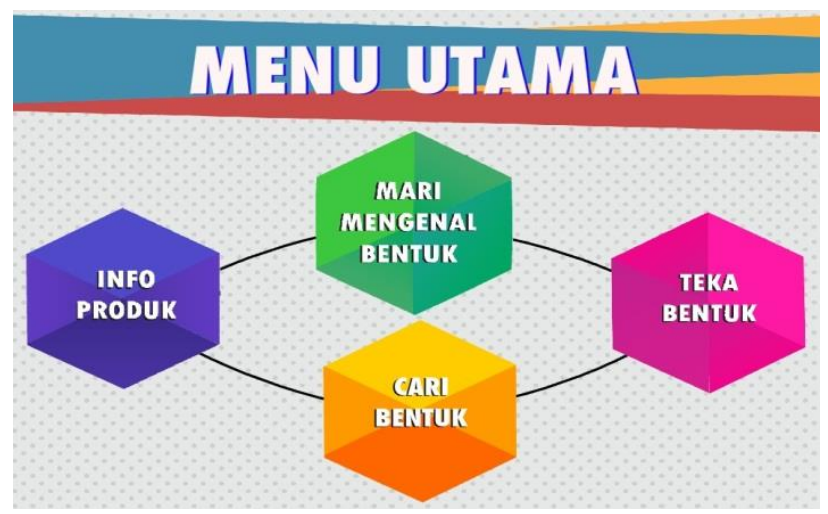

Figure 2. The main menu of the mobile application Learning Shape

c. Post-Test 
After all the participants had used the mobile application Learning Shape, they were given same pre-test question again (see Figure 3). All the answer will be checked and give scored.

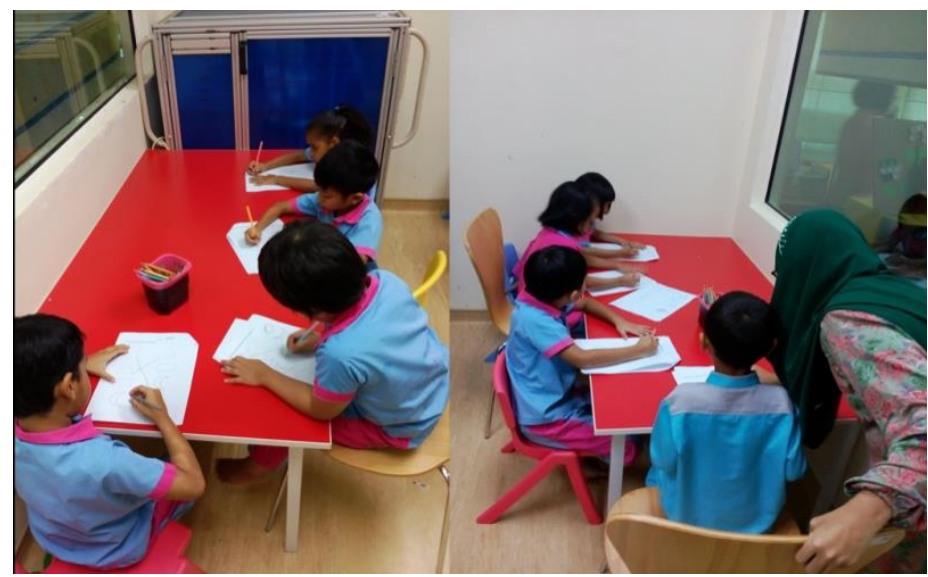

Figure 3. The preschool children were answering post-test questions

\section{RESULTS AND DISCUSSION}

The purpose of this study was to investigate whether the free-rotate gesture on multi-touch screen design would give effect to preschool children's achievement in learning about shape. The SPSS results presented in Table 1 and Table 2:

Table 1 Paired Samples Statistics

\begin{tabular}{llll}
\hline Age & & Pre-test Score & Post-test Score \\
\hline 5 Years & Means & 22.70 & 23.30 \\
\hline & $\mathbf{N}$ & 10 & 10 \\
\hline & SD & 3.561 & 2.869 \\
\hline 6 Years & Means & 18.50 & 22.90 \\
\hline & $\mathbf{N}$ & 10 & 10 \\
\hline Total & SD & 4.972 & 1.912 \\
\hline & Means & 20.60 & 23.10 \\
\hline & $\mathbf{N}$ & 20 & 20 \\
\hline & SD & 4.728 & 2.382
\end{tabular}

Table 2 Paired Samples Correlations

\begin{tabular}{l|l|l}
\hline \multicolumn{1}{c|}{$\mathbf{N}$} & Correlation, $\mathbf{r}$ & Sig. \\
\hline $\begin{array}{l}\text { Pre-test Score } \\
\text { Pre-test Score }\end{array}$ & .209 & .032 \\
\hline
\end{tabular}


Null hypothesis: There is no effect of the use of free rotate gesture in multi-touch screen design on the childrens' achievement in learning shape for pre-school children.

Alternative hypothesis: There is an effect of the use of free rotate gesture in multi-touch screen design on the childrens' achievement in learning shape for pre-school children.

Based on the Table 1, the total means for pre-test is 20.60 while total means for posttest is 23.10 for both group preschool children aged 5 and 6 . The results indicated that the posttest mean is higher than the pre-test mean. In addition, according to Table 2, it reported that Pre-test Score and Post-test Score are significantly positively correlated $(r=.209)$ and the value of sig $(\mathrm{p}=.302)$ which is $\mathrm{p}<.05$ showed that there is significance difference between pre-test score and post-test score. Null hypothesis is rejected and Alternative hypothesis is accepted. This statistical data proved that the free rotate gestures in multi-touch screen designs effect on childrens' achievement in learning shape for pre-school children in National Children Development Research Centre (NCDRC), UPSI.

Table 2 and Table 3 summarize the findings based on the observed learning behaviours of the five-year-old and six-year-old children.

Table 2 The post-test observed behaviors of five-year-old preschool children in learning shapes using free-rotate hand gestures

\section{Rubric Observation}

- At the beginning, Children 1 was too shy but starting to speak up when succeeding to rotate the shapes by using free rotate gesture and also can recognized basic shapes when queried by researchers.

- Children 2 did not show interest at the beginning because she did not succeed in rotating the shape but began to enjoy and show interest when she had rotate the shape

- Children 3 showed attentiveness in using free rotate gesture to perform the task on the multi-touch screen design

- Children 4 is very active and eagerly when handling the multi-touch screen design to rotate the shape

- Children 5 is active and interested in the use of free rotate gesture to solve the task on multi-touch screen design even though she is left-handed.

- Children 6 seemed happy and responds positively to researchers by answering the questions from them.

- Children 7 seemed friendly-type and she was too happy when using free rotate gesture to rotate the shapes.

- Children 8 showed interest to perform rotation task by using free rotate gesture though he was not familiar with the use of multi-touch screen design. 
- Children 9 interested to solve the task by using free rotate gesture and responds positively to researchers.

- Children 10 was active and feel it was fun when she successfully rotate the shape with free rotate gesture

Table 3. The post-test observed behaviors of six-year-old preschool children in learning shapes using free-rotate hand gestures

\section{Rubric Observation}

- Children 1 was passive but listen to the researcher's instructions very well.

- Children 2 was shy at the beginning but still had good cooperation with the researchers when rotating the shapes.

- Children 3 was hyperactive kid and need to be controlled by researchers to make him to rotate the shape by using free rotate gesture.

- Children 4 was shy at the beginning but began to response positively when using the mobile application Learning Shape. She was also aware with this application circumstances.

- Children 5 was active and show positive interest in using free rotate gesture on multi-touch screen design.

- Children 6 showed an interest in using this mobile application and was very interested in the "Cari Bentuk" game.

- Children 7 was very active and friendly with researchers while making rotations using free rotate gesture.

- Children 8 was eager to perform free rotate gesture and showed interest when asked by the researchers.

- Children 9 was active and happy when performing the rotation of shapes using the free rotate gesture on multi-touch screen design.

- Children 10 showed attentiveness in using free rotate gesture to perform the task on the multi-touch screen design

\section{CONCLUSION}

There are few studies exploring the impact of touch screen on children's cognition and learning even so touch screen devices are prevalent in children's way of life and influence children's 
development [17]. In this study, researchers used pre-and post-test paradigm to scrutinize whether using a free rotate gesture on multi-touch screen design could facilitate pre-schoolers in learning shapes. The results showed that the post-test score was higher than pre-test after preschool children used such free rotate gesture on mobile application Learning Shape to learn shapes.

\section{REFERENCES}

Radich, J. (2013). Technology and interactive media as tools in early childhood programs serving children from birth through age 8. Every Child, 19(4), 18.

Naismith, L., Sharples, M., Vavoula, G., \& Lonsdale, P. (2004). Literature review in mobile technologies and learning.

Celentano, A., \& Minuto, A. (2008, September). Gestures, Shapes and Multitouch Interaction. In Database and Expert Systems Application, 2008. DEXA'08. 19th International Workshop on (pp. 137-141). IEEE.

Hamza, Z. (2014). Study of touch gesture performance by four and five year-old children: Point-and-touch, dragand-drop, zoom-in and zoom-out, and rotate (Doctoral dissertation, Minnesota State University, Mankato).

Yu, X., Zhang, M., Xue, Y., \& Zhu, Z. (2010, June). An exploration of developing multi-touch virtual learning tools for young children. In Education Technology and Computer (ICETC), 2010 2nd International Conference on (Vol. 3, pp. V3-4). IEEE.

Wu, M., \& Balakrishnan, R. (2003, November). Multi-finger and whole hand gestural interaction techniques for multi-user tabletop displays. In Proceedings of the 16th annual ACM symposium on User interface software and technology (pp. 193-202). ACM.

Clarke, B., \& Svanaes, S. (2014). An updated literature review on the use of tablets in education. Tablets for Schools. UK: Family Kids \& Youth.

Agostinho, S., Tindall-Ford, S., Ginns, P., Howard, S. J., Leahy, W., \& Paas, F. (2015). Giving learning a helping hand: finger tracing of temperature graphs on an iPad. Educational Psychology Review, 27(3), 427-443.

Dubé, A. K., \& McEwen, R. N. (2015). Do gestures matter? The implications of using touchscreen devices in mathematics instruction. Learning and Instruction, 40, 89-98

Parnell, W. A., \& Bartlett, J. (2012). iDocument: How smartphones and tablets are changing documentation in preschool and primary classrooms. Young Children

Omar, A. (2017). Permainan Mudah Alih dan Kanak-kanak. IDEALOGY, 2(1), 137-149.

Hoggan, E., Williamson, J., Oulasvirta, A., Nacenta, M., Kristensson, P. O., \& Lehtiö, A. (2013, April). Multitouch rotation gestures: Performance and ergonomics. In Proceedings of the SIGCHI Conference on Human Factors in Computing Systems (pp. 3047-3050). ACM.

Nimbarte, M. (2011). Multi-touch screen interfaces and gestures analysis: A study. Advanced Computing, 2(6), 113.

Bertolo, D., Nigay, L., Pelurson, S., \& Vivian, R. (2015, October). Exploratory experimentation of three techniques for rotating a 3D scene by primary school students. In Proceedings of the 27th Conference on l'Interaction Homme-Machine (p. 43). ACM.

Dauksas, L., \& White, J. (2014). Discovering Shapes and Space in Preschool. Teaching Young Children, 7(4), 22-26.

Shape and Space, Accessed from https://www.earlychildhoodireland.ie/shape-and-space/ [Accessed April, 20, 2017]

Bedford, R., de Urabain, I. R. S., Cheung, C. H., Karmiloff-Smith, A., \& Smith, T. J. (2016). Toddlers' fine motor milestone achievement is associated with early touchscreen scrolling. Frontiers in psychology, 7. 